\title{
The Growth of Vegetable Plankton in the Sea.
}

THE changes in the plankton and their relationship to chemical and physical factors has long been a subject of inquiry, which is now being actively prosecuted along several lines. At the moment of writing, two research vessels on cruises round the world are investigating the distribution of manurial salts in the ocean waters and their relation to the quantity of planktonic life; the Meteor expedition in the South Atlantic has collected numerous data, and investigations are in progress on the Norwegian coast, off Heligoland, in the English Channel, and will shortly be instituted on the Great Barrier Reef upon varying facets of the same question.

Until recently it was only in isolated cases that more than a general relationship has been made out. out, to be followed by a succession of further flowerings. Each outburst was accompanied by an increase in oxygen, a fall in carbon dioxide--lowering the hydrogen ion concentration-and a fall in phosphate content of the water in the upper layers. A noticeable lag occurs between the commencement of a flowering and a fall in phosphate, and was also apparent with the changes in oxygen and carbon dioxide content of the water.

It is remarkable that the April outburst dies away and a week elapses before the second outburst starts in May, although phosphate available for growth remained in the upper layers. Again, the paucity of diatoms from June 4 until June 29 is not accompanied by a complete lack of phosphate.
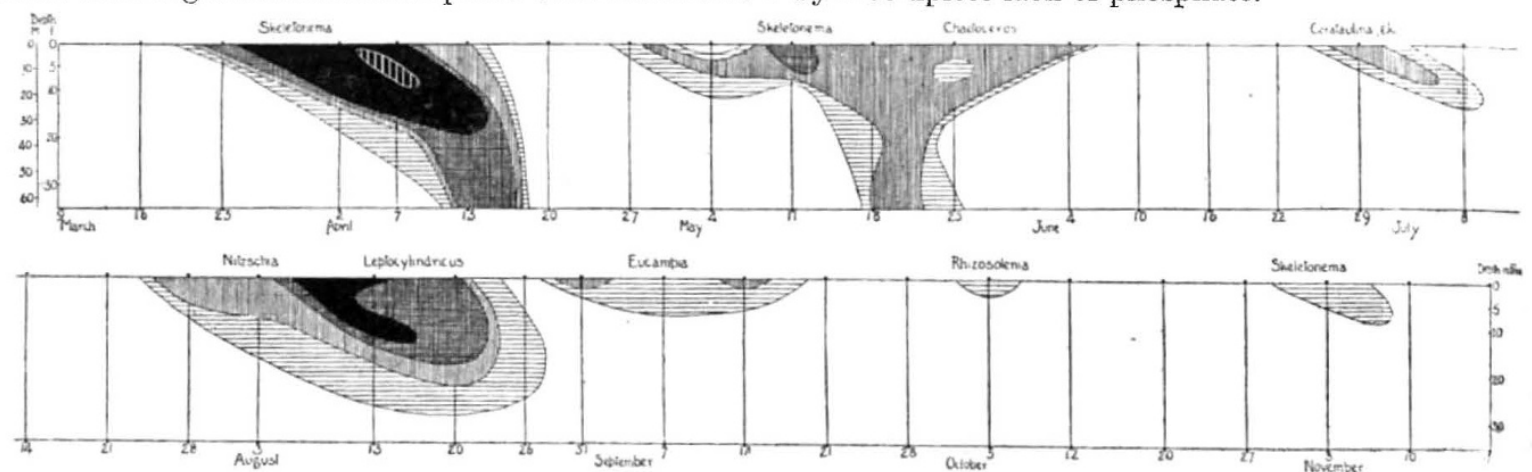

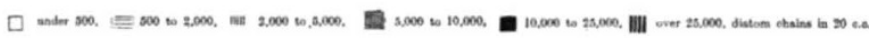

FIG. 1.-Diagram of the Diatoms at Clapochlar in 1926.

The work of Marshall and Orr $^{1}$ in Loch Striven, on the west coast of Scotland, during 1926 and previous years, has afforded a noteworthy addition to our knowledge of the physical and chemical conditions which accompany the outbursts of diatom growth in the sea--complementary to the work of Gran and his coworkers, and to that of Screiber, which were proceeding at the same time from a similar biological viewpoint.

Loch Striven lent itself readily to such an investigation, since it was found, from general surveys, that the outbursts of diatoms were similar in kind and in time to the outbursts in other positions in the Clyde sea area. The water is not polluted by any village on the shore, and the land area draining into it is only twice the area of the loch itself. The loch was visited weekly during 1926, when the diatoms occurring at various depths were ascertained, together with the phosphate, oxygen, and salt content of the water, its temperature and hydrogen ion concentration. Nitrate and nitrite were always found in the water, but the presence of iron oxide in the water, washed down from the hills, was thought to vitiate the method of nitrate analysis employed.

The successive growths or 'flowerings' of diatoms is clearly shown in Fig. 1. They commenced near the surface, extending into deeper water and then dying

1 " The Relation of the Plankton to some Chemical and Physical Factors in the Clyde Sea Area," by S. M. Marshall and A. P. Orr. Jour. Marine Biological Association, vol. 14, pp. 837-868; 1927.
Provided there was also nitrate available for their growth, these intervals indicate that the diatoms require some other factor besides light and nutrient salts, or possibly that they excrete some substance inimical to their future growth, as was suggested by Nathansohn in 1909, but for which there is no definite evidence.

The succession of outbursts in the loch during summer are more numerous than the 'usual' outbursts in the open sea, and this is attributed to vertical mixing during the summer months, caused by strong winds blowing up or down the loch, and refreshing the phosphate-depleted upper water stratum.

Another point of difference from the open sea is that the spring outburst of diatoms has been shown to depend largely upon the amount of sunshine in the early part of the year in the English Channel and near the Isle of Man, whereas in Loch Striven during the years investigated it actually occurred latest in the year with most early sunshine.

Dinoflagellates occurred irregularly but were never numerous, except in the surface layers during the summer months, appearing and disappearing suddenly. They were most numerous near the head of the loch and their development was apparently related to changes in temperature and dilution with rainwater. They caused no noticeable change in carbon dioxide or oxygen content of the water.

H. W. H.

\section{Wool and Wool Fibres.}

$\mathrm{R}$

ECENT activities of the British Research Association for the Woollen and Worsted Industries have included a visit by two members of its staff to certain of the textile centres of Belgium, France, and Germany. The Association has by this means endeavoured to secure first-hand information of the

scientific work in connexion with wool and wool fibres which is being undertaken in those countries. It has also sought certain statistical information relating to the industry.

A report recently published by the Association No. 3068 , VoL. 122] gives an account of the institutions which were 
visited and of the statistics which were obtained. The statistical portion of the report would lay no claim to completeness. Similar but more extensive information is included in the very useful appendices to the Survey of the Textile Industries published by Sir Arthur Balfour's Committee on Industry and Trade. Such statistical reports, in view of the somewhat meagre information which has hitherto been available, are of considerable value to the industry itself.

The report makes special reference to the work on the constitution of cellulose upon which Dr. R. O. Herzog and his colleagues are engaged at the KaiserWilhelm-Institut für Faserstoffchemie, Berlin-Dahlem. Their work, which is based on the crystalloid theory of the structure of the wool fibre, has involved the considerable use of X-ray methods. The crystalloid theory of the wool fibre is not, of course, new. It does, however, provide a useful application of the relatively new conception of colloids of definite volume. Dr. Herzog gave a complete exposition of this work and of his own investigations in this connexion, at the spring conference of the Textile Institute, which was held in Cologne. A full account of the work appears in the Journal of the Textile Institute. Amongst other important investigations upon which Dr. Herzog is engaged, is the examination of the elastic properties of fibres. This work is of obvious importance to wool textile technologists.

Dr. Paul Krais, who directs the Deutsches Forschungsinstitut für Textilindustrie at Dresden, has devised an apparatus by means of which the evenness of stretch of fibres is being automatically recorded, apparently with rapidity and precision. He is also experimenting with a machine designed to measure felting properties. He appears to be able to secure that standard squares of cloth woven in different manner are subjected to uniform felting action under standardised conditions.

The portion of the report devoted to the activities at the Institut für Tierzucht at Hanover, and at Verviers and Roubaix, is likely to be of special interest to those actually engaged in the industry. At Hanover some three hundred students are being trained in animal husbandry under Dr. H. C. C. Kronacher, who is, of course, well known for his work on sheep breeding problems. At Roubaix and Tour. coing special attention is being given to the classing and sorting of wools. In its reference to this matter, the report contains the statement that the initial operation of wool sorting in England differs fundamentally in principle from that performed in France. In particular it asserts that " while in Bradford wool is sorted according to length of fibre, in Roubaix and Tourcoing it is sorted according to fineness." This statement appears to be misleading, as it does not represent entirely the current trade practice in Bradford wool-sorting warehouses.

The Association intends to continue the survey which it has initiated through these continental visits, by sending a member of its staff to Australia, New Zealand, South Africa, and Canada. The cost of this projected survey is to be met by the Empire Marketing Board, which has made a special grant of $£ 2000$ a year for two years to the Association. The survey is to include a study of sheep populations, of systems of management and marketing, of the relationship of wool to mutton production, of the distribution of breeds and types, and of the effect of climatic eonditions and nutrition. The analysis of the various wools from the different colonies will form a complementary piece of work which will be undertaken in the laboratories of the Association.

\section{The Fossil Redwoods of the Manchurian Coal Deposits.}

IN recent issues of Science News-letter, issued by 1 Science Service of Washington, D.C., Dr. R. W. Chaney discusses his discoveries of fossil redwood remains in the Manchurian coal deposits, and describes some investigations carried out in the arid region of the Gobi in Mongolia. It will be remem. bered that it was in this region that the expeditions of the American Museum of Natural History discovered the famous dinosaur eggs.

Dr. Chaney's investigations afford some light on the botanical and climatological conditions of the Gobi in geological times. He has been unable to find that the Gobi region has ever supported a rich forest of the Manchurian redwood type, or indeed any extensive forests at all. During the Cretaceous period, which was the time of the dinosaurs, the dominant trees were Araucarias, modern forms of which are known in cultivation as the monkey-puzzle tree, Norfolk Island pine, and by other names. They are now native only to lands in the southern hemisphere, especially in South America. The living Araucaria species all prefer cool, rather dry habitats, and independent geological evidence connected with the dinosaurs indicates that the Mongolian species of these great lizards were dry land, cool climate animals. Thus we have two lines of evidence that the Gobi of two million years ago was more or less like the Gobi of to-day; not so dry, perhaps, but certainly not a moist country, and subject to a rather cool climate.

Other fossils of a later date, the Tertiary, when the dinosaurs had become extinct, show that the Gobi had still much the same kind of climate. At present there are no trees at all in the Gobi proper, but in the canyons of the Altai Mountains, which extend out into it, there are numerous cotton-woods and shrubby junipers. These species, growing under conditions of low rainfall which make life possible for most woody growth, may be supposed to reflect the environment in Mongolia during the Tertiary, a suggestion which is amply supported by the associated fossil animals. These are almost entirely of types found in the plains, including none of the forest animals which should be preserved in the rocks had there been widespread forests in Mongolia during that period.

From the point of view of former tree distribution in Manchuria the work of Dr. Chaney unfolds a fascinating page. The forests that grow in northern California to-day, it is said, are so much like those Manchurian forests of millions of years ago that only an expert professional botanist could tell them apart. The track of the ' march of the redwoods,' as the author expresses it, was found associated with the great Manchurian coal deposits, some of which are already being worked. Mixed with the fossil records of the redwoods, though in far smaller amounts, were alder, oak, maple, and fern.

Dr. Chaney postulates the question: What was their line of march? Did they originate in the Old World and cross over to the New by way of the Bering Straits region, as the human race is assumed to have done? Or did they evolve first in America and go west until they reached Asia? He wisely refrains from giving an answer at present, until further research work has been undertaken in connexion with this absorbing problem. He refers to a hint, from the distribution map of the finds of redwood fossils, of a possible third alternative. These finds are spotted away up in the Arctic: in Spitsbergen, on the west coast of Greenland, on the waste tundras of northern Canada, and one find far up amongst those desolate islands north of Baffin Land 